\title{
Models, Techniques and Indicators of Quality Management Assessment in Manufacturing Industries Over the Past Decade
}

\author{
Atieh Tavakoli ${ }^{1}$, Amir Azizi $^{2}$ \\ ${ }^{1}$ Science and Research Branch, Islamic Azad university, Iran \\ ${ }^{2}$ Science and Research Branch, Islamic Azad university, Iran (azizi@srbiau.ac.ir)
}

\begin{tabular}{|c|c|}
\hline ARTICLE INFO & ABSTRACT \\
\hline $\begin{array}{l}\text { Keywords: } \\
\text { Quality } \\
\text { Quality management } \\
\text { Quality Criteria } \\
\text { Quality Assessment }\end{array}$ & $\begin{array}{l}\text { In this study } 36 \text { articles from reputable databases; "Scopus", } \\
\text { "TPBin", "google Scholor", and "Research Gate" have been } \\
\text { considered. The focus of this paper was on manufacturing } \\
\text { industries key issues of quality management has been recited and } \\
\text { analyzed in this research ways. Therefore, on the basis of } \\
\text { previous studies and evaluations, the involved components in the } \\
\text { field of quality management have been investigated as the } \\
\text { competitive advantages. During a period of } 10 \text { years since } 2008 \\
\text { to } 2018 \text { as well as } 1386 \text { to } 1396 \text {, various researches have been } \\
\text { carried out in the field of manufacturing industries which } \\
\text { indicate the importance of this managerial aspect and preference } \\
\text { of top managers to improve production and optimization of the } \\
\text { resources of their companies. Finally, models, common } \\
\text { techniques and various measurement indicators of Quality } \\
\text { Management along with important points and efficiency level of } \\
\text { each of them have been identifies and presented. }\end{array}$ \\
\hline
\end{tabular}

\section{Introduction}

Service is a kind of product that has a significant share in the business and has enjoyed high qualitative and quantitative development in the third millennium. Services and quality have become a key tool in achieving competitive differentiation and promoting loyalty of customers. Today, the issue of products and services is a major problem that has affected all societies. Different communities are confronted with the issue of providing services and products for their survival. They try to optimize their services and products, according to the existing conditions and facilities. So, it can be claimed that management to provide these services and products is the necessity of any community (Alwani, 2010). On the other hand, today, quality has also been considered as the most important competitive advantage in the world. Since, organizations have suffered a lot from low quality, creating a system for quality management seems to be essential. This revolution is shaped by a small group of quality experts among which Edwards Deming is the most prominent one. The general term used to describe this revolution is "Total Quality Management (TQM)".

Generally, product quality is one of the most important characteristics from the point of view of manufacturers and consumers in various industries. In the current competitive world, improving product quality for companies is essential. Various approaches have been proposed in this regard, one of which is Quality Function Deployment (QFD). QFD is one of the most important ways to support product planning. QFD, through customer surveys, converting demands into engineering features and its special process, allocates resources to production

* Corresponding author E-mail address: Atiehtavakoli8@gmail.com

2538-8053/ @ 2018 IJARME. All rights reserved. 
and services, optimally (John et al., 2014). Hence, addressing this issue will have interesting results for manufacturing and service companies. The concept of QFD was first introduced by Professor Yoji Akao in 1966 and published in 1969 as a scientific paper by him. Generally, Quality Management in the industry sector is to monitor the production process to ensure conformity of product with desired design of the designer or the employer. Hence, the Quality Management covers a wide range of activities, including accessibility, easy transportation, low energy consumption, ease of training and product use, as well as maintenance and recycling. Today, problems in manufacturing and industrial projects such as the use of undesired materials, inadequate quality of implementation, lack of attention to the work environment and human resources and cost of rework activities have led to the creation of Quality Management Control System in the body of countries' industry to create favorable quality in industrial products (Sadikoglu, Zehir, 2010). Different industries are of great importance due to the allocation of a large part of the budget of countries to them. Therefore, applying quality management in order to achieve continuous empowerment, meet the needs of the applicants, increase synergy and productivity, increase employee participation and teamwork leads to significant profitability and trust among competitors. The aforementioned set of factors about quality and its significant role in industry has attracted attention to this issue.

\section{Definitions and concepts}

Quality is technically applied in its Relative Concept and this is the concept that is used in Quality Assurance and TQM. The word "quality" refers to various items such as degree of excellence, degree of compliance with the standard, special characteristics and desirable attributes. Since the concept of quality is a value based issue, it has a multidimensional nature and perceptions. Quality can be defined as doing things properly and continuously in all levels of the organization. It means that quality is a factor that creates balance among the needs of customers, employees, and financial goals of the organization. Doing things properly and continuously means providing customer's demands to achieve customer satisfaction. Quality means expressed or implied demands of the customers. Quality refers to the necessity of producing products and services in a continuous manner, with emphasis on the demands of customers. TQM is a management philosophy that is widely used in public and private companies and will lead to higher service and product desirability and lower costs. Quality is not revolutionary, and in fact it is everything other than revolutionary.

The nature of quality is really simple and according to Philip Crosb who is strongly impressed by the thoughts of Deming and Joseph M. Juran: " Quality has no limitation". Also, the chairman of Philips Company believes that "quality is lifestyle". These words seem to be slogans, but they are correct. It is difficult to apply the "quality approach" in companies and its starting point is not clear. But related researches indicate that the basic principles of quality management are well known in these organizations. The purpose of these principles is to meet the needs of customers through a continuous improvement process based on the commitment of management and the participation of all employees in the organization. Such a goal will evolve through TQM in organizations and may even provide a new management philosophy. In order to ensure the success of the quality approach, customer satisfaction should be considered as well as employee satisfaction. The Japanese consider quality precisely as goodness and quality management as In-house tools to enhance the product's quality not seducing the customer and attracting his apparent satisfaction. From Deming's point of view, quality is defined as: "Quality is predicting customers' future needs". In fact, the primary goal of any organization must be to achieve the highest level of customer satisfaction, not more profit, because their satisfaction will in itself increase the profit.

Quality as one of the oldest documented principles has different definitions. In the simplest case, the quality in the manufacturing industry and from the customer's point of view is nothing 
but satisfaction in the field of appearance and its level of effectiveness (Jha and Iyer, 2006). Today, quality is the top issue in organizations and it can be claimed that quality improvement is one of the most important challenges that any institution faces. The best organizations understand the quality and its secrets. Considering the world of commerce, we can find the starting point of quality debates. I.B.M Corporation defines quality as "Customer Satisfaction". Quality is a "thought" that arises at the right time and most companies and organizations regard it as a value. From another perspective, the concept of quality is the measurement of predetermined standards and compliance with those standards. Indeed, observance of related standards while providing a product, shows the quality of that product or service. Also, quality in industry is defined as: the compliance of the product with its manufacturer's claim. This aspect of quality is known as "work quality". Work quality is the basis of quality assurance systems. The focus of the nature of quality is on the core role of the customer. In order to nourish the concept of quality in any organization, indicators such as acceptability, timely delivery and price should be determined for each product. It should be noticed that an important characteristic of any product is its durability over a specified period of time in order to meet the customer's needs. Finally, it should be said that quality as an independent and comprehensive concept, shows characteristics and ability of a product to meet the implicit and specific needs. This definition is applicable within the framework of manufacturing industry, organizational thinking and related services and covers different aspects and dimensions of quality in various fields.

\section{Techniques and models in the field of quality}

TQM is a complete and efficient management philosophy that properly addresses the issues of quality and customer satisfaction. In the current world, with regard to the national, regional and international competitions, and also fast changes and developments in technology, market demand, etc., the analysis of correct cognition and proper use of topics such as TQM can be effective.

- TQM model in the field of quality management

Trend towards quality has been recognized as a competitive advantage in recent years. According to the previous studies, companies need to focus on competitiveness to survive and stay in the market. One of the competitiveness edges is "quality" that is achievable through implementation of key components of TQM. Ismail Sila (2009) in his study proved that "TQM has a direct impact on financial performance and market outcomes, customer results, employee outcomes, organizational effectiveness, and performance".

- Analysis and evaluation of the efficiency of TQM model

TQM is an important managerial style that focuses on continuous improvement of the quality of products and services to provide customers' needs. Quality and continuous improvement have a fundamental role in development. In order to achieve a superior level and excellent quality in the organization, an integrated management system is needed to put all the organizational factors on the basis of quality. Manufacturing organizations and industries Are the main pioneers in this field (Mustafa, Bon, 2014). Key aspects of TQM are prevention of waste and emphasis on design stage. Gopal kanji states the reasons of the necessity of implementation and establishment of TQM as follow:

- Today's competitive world

- Customer Satisfaction

- Improvement of staff morale

- Improved performance

- continuous improvement

- Attracting more customers

- Encouraging teamwork

- Minimizing costs 
- Overcoming weaknesses and solving current issues

- competition to attract capital

- change management

- Promoting a positive culture (Gopal kanji)

\section{Six Sigma Model in Quality Management}

Definition of elements, measurement, analysis, and promotion of customer satisfaction, especially in service delivery systems, has been highlighted in recent years. Six Sigma is a newly developed method, introduced by Bill Smith, one of the Motorola company's top experts, on January 15, 1987. Six Sigma is a systematic approach that helps organizations improve the quality of their products and services to meet the customers' needs (Dehvari, 2014). The basic purpose of Six Sigma method is to achieve strategic implementation based on performance measurement through execution of improved projects. Six Sigma attempts to reduce process fluctuations by the use of two approaches named DMAIC ${ }^{1}$ and DMADV ${ }^{2}$. DMAIC process is an improvement system for processes which are not in accordance with performance specifications required by the customer or top managers. DMAIC stands for Definition, Measure, Analyze, Improve and Control, as shown in Figure 8-A.

DMADV process is an improved system for creating a new process or product that we want it to achieve the six sigma quality level. For an organization that has reached six sigma level, $99 \%$ of the opportunities are not mistakes. when you can not improve the performance of the existing process beyond the current level, you can use this method.

Six Sigma is a data-driven approach aimed at achieving superior quality. Six Sigma focuses on failure prediction. Six Sigma is an ordered and structured effort that addresses the organization's repeatable processes in different sections. The objectives of Six Sigma in the field of quality management consists of reducing fluctuations and changes, reducing deficiencies, improving process efficiency, increasing customer satisfaction, reducing costs, improving quality, systematic approach to problem solving, strengthening the competitiveness of the organization and reducing delivery time (Motaqi. 2010).

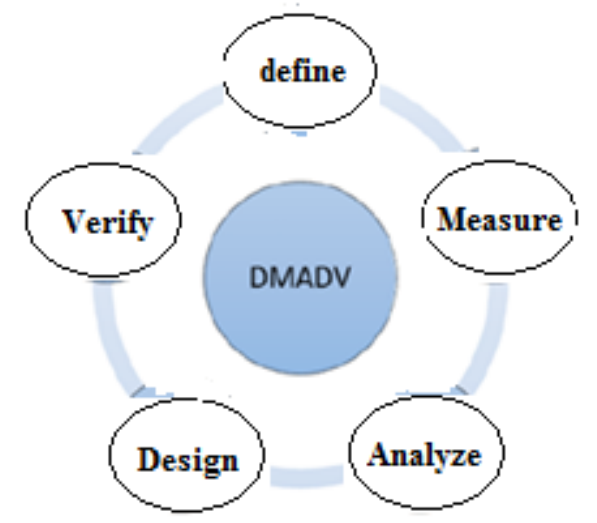

figure 1.b. DMADV precess components

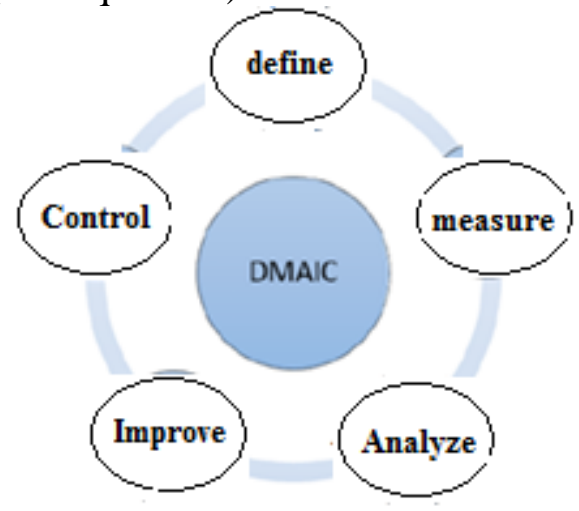

figure 1.a. DMaIC precess components

\section{- Performance Evaluation and Analysis of Six Sigma Model}

Six Sigma is a statistical method that defines customer needs as separate tasks and considers related optimal features. Therefore, it has a deep impact on product quality, customer service performance and professional progress of personnel. Since, Six Sigma focuses on statistical analysis, design evaluation scales and product development, it is able to reduce the likelihood of the errors in productions and services. Six Sigma model is the result of the social and

1 . Define, Measure, Analyze, Improve, Control

2 . Define, Measure, Analyze, Design, Verify 
technical system link. In fact, Six Sigma is the guide to survival and success which will result in good performance.

Table 1- Comparison of Six Sigma Model and TQM

\begin{tabular}{|c|c|c|}
\hline Num & TQM model & Six Sigma Model \\
\hline $\mathbf{1}$ & $\begin{array}{c}\text { Focus on the organization's } \\
\text { concentration on understanding and } \\
\text { responding to customer needs }\end{array}$ & $\begin{array}{c}\text { Continuous effort to reduce the output } \\
\text { deviations of key processes of } \\
\text { Business success }\end{array}$ \\
\hline $\mathbf{2}$ & $\begin{array}{c}\text { Systematically Continuous } \\
\text { improvement of all products and } \\
\text { services and processes }\end{array}$ & $\begin{array}{c}\text { Manufacturing and business processes can } \\
\text { be measured and } \\
\text { Analyzed }\end{array}$ \\
\hline $\mathbf{3}$ & participation of all partners & $\begin{array}{c}\text { Continuous improvement of quality } \\
\text { requires commitment of the entire } \\
\text { organization, especially senior } \\
\text { management }\end{array}$ \\
\hline
\end{tabular}

\section{SCQM model in the field of quality management}

Considering the paradigms of other types of quality management models, researchers have developed a concept called "Supply Chain Quality Management", which is considered as the final step to achieve "TQM" through which companies will be able to integrate concepts of two Management Philosophy of Total Quality Management and Supply Chain Management (SCM) and as a result enhance supply chain performance and the quality of final products to gain competitive advantage. Mullatra and Robinson define Supply Chain Quality Management as follows: Formal coordination and business process integration of all organizations involved with the supply chain in order to measure, analyze and improve the quality of products, services and processes that lead to the creation of value added and customers' satisfaction. Lee and Chaung (2010) believe that: Although SCM and TQM have historically two different starting points, but as time passes, these two philosophies have become closer and closer to each other because of their ultimate goal (customer satisfaction) and the integration of these two methods in the current situation is essential.

- Analysis and evaluation of efficiency of SCQM model

Nowadays companies have to cooperate extensively and closely with other companies involved with the supply chain in order to improve their product quality. Therefore, in "Supply Chain Quality Management", there should be a platform for effective cooperation of the supply chain members in this field. Supply chain management provides supply chain members with an effective link among them, to provide them with the opportunity to be able to collaborate and participate more effectively in improving the quality of their products and services (El Ouardigh, 2014). These dimensions include: customer concentration, supplier quality management, Supply Chain Quality leadership, Supply Chain Quality Strategies, Process Approach, Supply Chain Quality Information Systems, and Human Resource Development in the Supply Chain.

Considering the efficiency and dimensions of this model, we can say that the most important indicators of SCQM quality model are as follows:

1. Existence of mechanisms, infrastructures and tools for systematic management of customer relationships.

2. Existence of mechanisms, infrastructures and tools for systematic management of supplier relationships.

3. Knowledge and ability of top managers in quality and supply chain quality management.

4. Integrity and compatibility among different types of processes at the supply chain level (do Nascimento, 2013). 
- Servqual model in the field of research services quality

Generally, service and service quality are considered as the characteristics of the survival of organizations in the current competitive world. This fact is also true about the research services. Assessment and control of operations within the organization is one of the ultimate goals of the management accounting process. In this regard, various scientific tools and models are used in accordance with the status and performance of each organization (Zimmerman et al, 2011). Servqual model is a valid and popular service quality measurement model that uses a standardized questionnaire tool. This model was first introduced by Parasuraman and Zeithaml. Servqual model is a prominent approach for quantitatively assessing service quality. The Servqual model, using a research approach, extracts the expectations and audience perceptions of each of the five dimensions and their attributes, which results in identifying the gap between expectation and perception. These dimensions include:

1. Appearance: Physical features, equipment, staff appearance, and so on

2. Reliability: Ability to provide services accurately

3. Responsiveness: The desire to help and meet customer needs

4. Guarantee: The ability of employees to create trust and confidence

5. Empathy: Paying special attention to each customer

Parasuraman and Zeithaml (2010) define service quality as the difference between customer expectations of performance and his perception of real performance and believe that service quality is equal to service performance. Perez et al. (2009) have defined service quality based on its three distinct features:

1. Service quality will be consumed at the same time it is produced, so the consumer will figure out all service quality defects.

2. Quality service is a set of benefits, but it is often recognized as an experience.

3. The quality of relationships between service providers and consumers is one of the essential aspects of service quality.

- FMEA model as the quality management technique

FMEA model is a systematic approach or methodology that is used for the following reasons:

1. Identifying and prioritizing of potential failures in a product, process, or service system.

2. Definition and implementation of special measures to eliminate or reduce the occurrence of potential failure scenarios.

3. Documenting the results of the analysis to provide a complete reference for solving future problems.

In other words, FMEA is an analytical technique based on "prevention before occurrence" law that identifies potential failure factors. This technique focuses on enhancing the security factor and customer satisfaction through the preventing potential failure. One of the success factors of FMEA is its implementation time.

FMEA is a low-risk instrument for predicting problems and deficiencies in design phase or development of processes and services in the organization.

\section{- Examining and analyzing the performance of FMEA model}

FMEA is a dynamic tool used in the continuous improvement cycle. FMEA does not solve problems alone but should be used along with other problem-solving techniques. In fact, this model measures performance and quality before mass production and distribution and as a result leads to reduced production costs. Because it does not allow breakdown in a wide range (Zen et al. 2015).

\section{Deming's Quality Cycle}

Implementing a quality management system is a strategic decision for the organization to improve its overall performance and provides a rational basis for sustainable development 
activities. PDCA ${ }^{3}$ as a four step business management method is used for continuously managing processes, products and services. This cycle is usually used in the following cases:

- A model for continuous system improvement

- Launching a new project

- New service, product or process development

- Definition of repetitive work process

- Prioritizing the data set and analyzing the main causes

- Applying changes to the system

- Assessing the activities of organization based on the steps of the Deming's cycle

This cycle consists of four executive steps:

- Plan: In the first stage, the current status of the study and the qualitative problems are identified and goals are set.

- Do: At this stage, the plan is prepared and performed experimentally and the results are recorded.

- Study (check): At this stage, it must be considered whether the specified goals are realized or not. If the answer is negative, the reason must be analyzed.

- Act: At this stage, the plan is implemented to identify qualitative problems and resolve them.

This cycle should be run regularly and periodically, that is, after running the fourth step, we should return to the first stage and check the status quo to improve quality constantly. This cycle encourages work to be done in a systematic way and with the problem-solving approach. PDCA concept is used in process improvement, change management, quality management, project control, efficiency management and organizational competition. This concept can be used in different phases of software production.

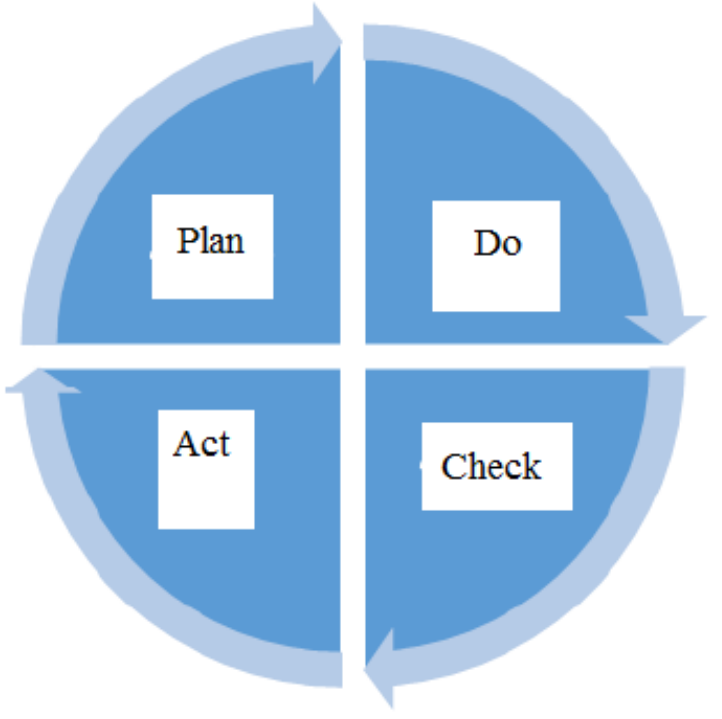

Figure 1. Deming's Quality Cycle

\section{Quality Measurement Indicators}

Quality can be considered as one of the main factors of productivity and satisfaction of customers for industrial companies. Although quality increases cost, but this improvement can be considered as the most important customer satisfaction factor in the complicated market of the industries. According to the previous studies, any attempt to increase quality will lead to 
increased costs. As a result, identifying and prioritizing the factors affecting the quality of projects in the industry will not only consider the quality but also control the increased costs (Omar and Murgan, 2014). Quality can be formulated in the following way:

P: Performance Q: Quality E: Expectations

$\mathrm{Q}=\mathrm{P} / \mathrm{E}$; If $\mathrm{Q}$ is greater than one, the customer will feel good while using that product or service. Finally, it should be said that quality is the set of features and attributes of a product or service that includes its ability to meet needs and demands. Generally, quality has 9 different dimensions, including performance, characteristics, compliance, reliability, durability, service, responsiveness, aesthetics and fame. Few products can be perfect in terms of all of these 9 dimensions. David Garvin has defined the eight dimensions that can be used strategically to analyze quality attributes. Improving one of these dimensions may lead to an increase in the cost of other dimensions. Among these eight dimensions, "understanding of the contract by the customer" can help to achieve competitive advantages. Eight dimensions of Garvin are summarized as follows:

1. Performance: The first operational attribute of the product that includes proprietary tokens.

2. Feature: It is the second aspect of the performance that completes the primary purpose.

3. Reliability: Probably, it is the successful operation of a particular purpose, for a determined period of time and given conditions. Reliability is often measured at the time of the first breakdown or between failures.

4. Compatibility: The degree to which the product design and operating characteristics are consistent with the established standards. Although this function is sometimes defined as the compliance with the requirements.

5. Durability: Measuring product life can be the amount of time to use a product before failure or the point where the substitution is preferable to repair. Durability is closely related to reliability and serviceability.

6. Serviceability: it includes speed, convenience, competitiveness, easiness and repair and repair costs.

7. Aesthetics: How to display a product, feelings, sounds, tastes and smells. Aestheticism is a personal judgment and the preferential reflection of different people and a dimensional issue.

8. Understanding Quality: Consumers often do not have complete information about product or service attributes. Indirect measurement

9. Or understanding quality may be a basic comparison of them with other product or service (Reza, Ali, 2017).

It is also necessary to identify the distinctions among three trends in the field of quality management (quality control, quality assurance and total quality). Quality control is one of the oldest quality concepts and includes searching and eliminating products or components that are not standardized. Quality assurance can be defined as a means to produce perfect products. Quality assurance deals with doing things correctly in the first step and all other stages. Total quality management is integrated with quality assurance and made it developed. TQM emphasizes on teamwork and presents a management approach that provides authorities beyond control and quality development. The focus of all members of the organizations is on the customer and everyone is looking for recognition, satisfaction, control and supervision of them.

\section{Review of the literature}

Review of the literature 
- Chopra \& sine (2015) believe that TQM system is an effective costing system for continuous quality improvement efforts at all levels of the organization to assure customer satisfaction and meet the changing and diverse needs of customers.

- Fernandez et al. (2014) presented the six operational dimensions of supply chain quality management as follows: Strategic management and planning, Engagement and commitment of employees / stakeholders, Information, Integrated and beneficial communications among suppliers, Leadership and Continuous Improvement and Innovation.

- Victor (2013) defines supply chain as all activities involved in the receipt of raw materials, delivery of products through customers, production and assembly, inventory tracking, order management, distribution among all channels, customer delivery and the need for information systems to control all of these activities.

- Kaynak (2013) has provided various definitions of Total Quality Management (TQM). He defines TQM as a comprehensive management philosophy that seeks to continuously improve all organizational operations. The goal of TQM is to be realized only if its concepts and principles are implemented from receipt of raw materials to after-sales service in the organization.

- Jay Paynebon \& Rao (2013) believe that various models such as ISO quality management standards, organizational excellence models 81 EFQM and 88 MBNQA have been proposed to implement quality management procedures. These models apply different procedures for operating the concept of quality management. For example, MBNQA model, examine and evaluate seven procedures. These procedures include leadership, human resource development and management, strategic planning of quality, customer concentration, quality management, information and analysis, operational results and quality.

- Robinson et al. (2011) define supply chain quality management as follows: formal coordination and business process integration of all organizations involved in supply chain in order to measure, analyze and continuously improve the quality of products, services and processes to achieve value creation and customer satisfaction.

- Lee and Cheng (2010) define Total Quality Management as the commitment of all employees to continuous improvement of the work processes with the aim of satisfying customers and meeting their requirements and needs.

- Fotopoulos, C.V. and Psomas (2010) state that what makes TQM different from other quality management systems, such as Quality Assurance Models, is the evaluation of the organization's performance, which takes into account the indicators such as customer satisfaction, employee satisfaction, environment and society and finally internal and external results.

- Riahi (2012) states that Total Quality Management is an approach based on which organization management with the participation of all employees, customers and suppliers addresses the continuous improvement of quality that leads to customer satisfaction.

- Ajali et al. (2017) defines supply chain quality as a mutual agreement between requirements and companies to improve the performance of exchanges of the supply chain.

- Azizi (2015) in his research has introduced decision support system (DSS). This idea includes efficient and effective use of production skills, time, space, money and other influential factors enabling the current system to work more economically. He believes that the challenges associated with decision making are large and sometimes complex, especially when faced with a wide range of factors and criteria for choosing. In practice 
many decisions are taken without a formal method or discussion, and such decisions often lead to conflicts and waste of resources. In this study, a decision model was developed to evaluate and select lean manufacturing tools for implementing the Lean methodology in the product assembly environment using the Kano's hybrid model and establishment of Quality Function. The mentioned hybrid method has been evaluated and simulated with numerical examples. The proposed model was found to be useful and effective in addressing the multi-criteria problems.

- Azizi (2015) in a study focusing on quality processes and increasing productivity in organizations states that organizations should develop the quality and efficiency of products and processes in order to survive in the competitive market. The integrated framework is a valuable approach for achieving this goal. In this study, important methods of TQM have been emphasized. Then, the probability of designing an integrated framework was evaluated that makes interrelation between the important methods and the priority of the effectiveness of each technique in successful implementation of TQM in Automotive Industry as a benchmark model possible. Modern quality paradigms emphasize on the importance of customer satisfaction as a stimulus to the development process. This study focused on six important factors of customer satisfaction. In this paper, an empirical study was conducted to confirm the importance of the effectiveness of important methods for improving the implementation of TQM. Integrated framework has been proposed using extracted knowledge and experience from industry and Academic Quality Officers in 120 Malaysian car companies. TQM's important methods are suggested to achieve better performance in the Automotive Industry using pair-wise comparison.

- Azizi et al. (2015) in a study considered the most important and prominent criteria of the supply chain in Automotive Industry to select the optimal methodology in this field. Supplier selection process is one of the key management activities in a supply chain environment. This research presented another way to select the most suitable supplier in a supply chain system using FTOPSIS. A triangular fuzzy set is applied to the proposed model for addressing unfamiliarity. The interdependence between the criteria is considered. The results showed that FTOPSIS is successful in determining the best stable supplier in ranking, because this issue is related to the weight of different criteria. The proposed method is a comprehensive multi-criteria approach to find the best ranking.

- Azizi (2015) in a research stated that recently, more attention has been paid to TQM's techniques in the manufacturing sector, especially in the Automotive Industry. This research was conducted with the aim of examining six techniques of TQM in Automotive Industry. The purpose of this research was to identify the relationships among the six critical techniques of TQM. This relationship has been identified through distributing questionnaires among 30 quality experts in 10 Automotive Manufacturing Industry in Malaysia. Among the key techniques of TQM the highest rate of relation was seen between SPC and FMEA, QFD and APQP, QFD and FMEA. The results emphasized on the importance of the communication level of the nine critical techniques in order to have a more effective and efficient quality system.

- Azizi (2007) in a study examined the nine techniques of TQM in Automotive Industry. To this end, six important criteria for a satisfactory prediction of Total Quality Management System have been proposed. This research has also been verified by Malaysian Quality Experts in Automotive Industry in this country. In this study AHP method was used which is a multi-criteria decision-making method (MCDM). The results showed that the priorities of the Total Quality Management System were satisfactory based on the ranking of its items. In addition, a sensitivity analysis was also 
conducted to demonstrate the reality of final results. Finally, the proposed AHP model was introduced as an optimized and efficient decision making model in the field of Automotive Industry Quality Management.

\section{Conclusion}

It can be concluded that quality managerial components have a superior position among top managers and industry owners. The current different techniques makes it possible for all organizations to be covered by quality management. Quality management has passed geographic boundaries and appeared in different forms and structures within the industry. Quality management system includes quality and customer satisfaction and covers management related issues and techniques. Accordingly, it can be claimed that overall framework of quality management includes three basic principles:

- Focus on the organization's concentration on understanding and responding to customer needs: interacting with customers to understand the level of current expectations or predicting future expectations will provide a designed process to link business efforts with customers.

- Continuous improvement of all products and services and processes: successful implementation of the Deming's cycle combined with the recognition of each process and measuring its efficiency, then making the understandable principles will start by applying it in production operations. The basic quality tool can now be extended to all tasks include information systems, marketing, finance, transportation, health care, education, organization, engineering, research and development, and so on.

Since each of the previous researchers has only considered one type of quality management systems, excellent results for industries and services have not been achieved. It can be suggested that since each of the existing models and techniques in the field of quality management considers some parts of the existing needs and given that each model of the quality management system includes a part of the organization's needs, researchers must combine and integrate more than one model and technique for dissemination of quality management by carefully examining critical points in organizations and industries to achieve better outcomes.

\section{Resources}

Abolhasani, R. (2015). Total Quality Management and Innovation. Quality Control, No. 41 Volume 8.

Ajali, M., Qasemian Sahebi, E. (2017). Ranking of Factors Affecting Supply Chain Quality Management in Gas Industry Using Gradual weight Evaluation analytical technique, Quarterly Journal of Amad Extension of Thought, No. 57 Fifteenth year.

Ali, M., \& Raza, S. A. (2017). Service quality perception and customer satisfaction in Islamic banks of Pakistan: the modified SERVQUAL model. Total Quality Management \& Business Excellence, 28(5-6), 559-577.

Alvani, M., \& Mir Shafiei, N. (2012). Production Management. 22nd Book, Mashhad, Astan Quds Razavi Publishing and Printing Company.

Ashrafi, M. (2010). Assessing service quality in public and private banking system using SERVQUAL 5-dimensional model, MSc in Business Administration, Islamic Azad University, Science and Research Branch of Tehran.

Azizi, Amir (2015). An Integrated Model of Kano and Quality Function Deployment for Evaluation of Lean Production Tools in Assembly Environment, Proceedings of the 2015 International Conference on Industrial Engineering and Operations Management Dubai, United Arab Emirates (UAE), IEEE, pp 1 - 6, DOI: 10.1109/IEOM.2015.7228097. 
Azizi, Amir, Daniel O. Aikhuele ,Fathi S. Souleman.(2015). A Fuzzy TOPSIS Model to Rank Automotive Suppliers. 2nd International Materials, Industrial, and Manufacturing Engineering Conference, MIMEC2015, 4-6 February 2015. Bali Indonesia.

Azizi, Amir. (2007). Satisfactory Prediction of Performance of Total Quality Management Critical Techniques, 13th Asia Pacific Management Conference's proceeding (APMC-2007), Melbourne, Australia, 18-20 November, pp 322-337.

Azizi,Amir.(2015). An integrated framework of critical techniques in implementation of Total Quality Management.Published in: Industrial Engineering and Operations Management (IEOM), 2015 International Conference on. Dubai, United Arab Emirates.

Azizi. Amir.(4185). Relationships between Total Quality. Management Critical Techniques in Automotive Industry. Proceedings of the 2015 International Conference on Industrial Engineering and Operations Management Dubai, United Arab Emirates (UAE), March 3 - 5, 2015.

Blanchard, D. (2010). Supply Chain Management - Best Practices (Second Edition ed.). New Jersey: John Wiley \& Sons. Inc.

Bon, A. T., \& Mustafa, E. M. (2013). Impact of total quality management on innovation in service organizations: Literature review and new conceptual framework. Procedia Engineering, 53, 516-529.

Chang G. (2009). Total quality management in supply chain. International Business Research. 2 (2): 82-85.

Chopra, A., \& Singh, B. J. (2015). Unleashing a decisive approach to manage quality costs through behavioural investigation. Business Process Management Journal, 21(6), 1206-1223.

Chung, T \& T, Sheng and Z, Yuan . (2008). "Auditing pricing decision: the role of institutional investor”. The Business Review, Cambridge. Vol 10. no 1. pp 75 - 81.

Clark, D. M., Silvester, K., \& Knowles, S. (2013). Lean management systems: creating a culture of continuous quality improvement. Journal of clinical pathology, jclinpath-2013.

de Sousa Jabbour, A. B. L., Jabbour, C. J. C., Latan, H., Teixeira, A. A., \& de Oliveira, J. H. C. (2014). Quality management, environmental management maturity, green supply chain practices and green performance of Brazilian companies with ISO 14001 certification: Direct and indirect effects. Transportation Research Part E: Logistics and Transportation Review, 67, 39-51.

Dehwari, M. (2013). Designing a Comprehensive System Model for Iran's Light Industries, Master's thesis, Zahedan, Nikbakht University.

do Nascimento Gambi, L., Gerolamo, M. C., \& Carpinetti, L. C. R. (2013). A theoretical model of the relationship between organizational culture and quality management techniques. Procedia-Social and Behavioral Sciences, 81, 334-339.

El Ouardighi, F. (2014). Supply quality management with optimal wholesale price and revenue sharing contracts: A two-stage game approach. International Journal of Production Economics, 156, 260-268.

Fernandes, Ana Cristena, Paulo Sampaio and Maria do Sameiro Carvalho (2014). Quality Management and Supply Chain Management Integration: A Conceptual Model, Proceeding of International Conference of Industrial Engineering and Operations Management. Bali. Indonesia. January 7-9.

Fernandez, L.M, Albacete-Saez, C.A. (2011). "Environment- quality management coalignment across industrial context: An empirical investigation of performance implications". Industrial Marketing Management, 40(1):730-742.

Fotopoulos, C.V. and Psomas, E.L. (2010).'The structural relationships between TQM factors and organizational performance".The TQM Journal, 22(5): 539- 552. 
Hamidizadeh, MR., Babaei, S. (2013). Effect of Total Quality Management Implementation on Improving Processes. Case Study: Khuzestan Economic and Asset Administration, Journal of Industry and University, The second year. Num: 9-10.

Jafarnejad, A. (2013). Production Management and Innovative Operations, Tehran University of Technology.

Jitpaiboon, T. and Rao, S.S. (2013). "A meta-analysis of quality measures in manufacturing system".International Journal of Quality and Reliability Management. 24(1):78-102.

John, R., Smith, A., Chotipanich, S., \& Pitt, M. (2014). Awareness and effectiveness of quality function deployment (QFD) in design and build projects in Nigeria. Journal of Facilities Management, 12(1), 72-88.

Kanji, G.K.,Wong,A.,(1999). Business excellence model for supply chain management.Total Quality Management10, 1147-1168.

Kaynak, H. (2013).'The relationship between total quality management practices and their effects on firm performance". Journal of Operations Management. 21(4):405-35.

Lee, M-C. and Chang, T. (4181). "Applying TQM, CMM and ISO 9001 in knowledge management for software development process improvement". International International Journal Services and Standards, 2(1):101-15.

Lee, S.-H., Y. Amer, and G. Fauza. (2013). Model of an Integrated Procurement- Production System for Food Products Incorporating Quality Loss during Storage Time. International Journal of Materials.Mechanics and Manufacturing, 2013. 1(1): p. 17-21.

Li Ling, Su Qin, Chen Xu (2011). Ensuring supply chain quality performance through applying the SCOR model. International Journal of Production Research; 49: 1, 33-57.

Mohamed Khaled Omar, Sharmeeni Murgan.(2014). An improved model for the cost of quality. International Journal of Quality \& Reliability Management. Emerald Group Publishing Limited. Emerald Group Publishing Limited. Issu4. Pages 395-418

Motaqi, H. (8817). Production and Operations Management, Fifth Edition, Tehran, Avaye Patris Publication.

Najati-Fard, M. (2016). A Study on the Establishment of Quality Management Systems in the Manufacturing Industry with Functional Objectives. Master's Thesis for Manufacturing Engineering Management, Faculty of Engineering, Tehran University.

Nikzad, M., \& Tayebi, M. (2015). The Impact of Establishing TQM System on Customer Satisfaction with the Purpose of Achieving Sustainable Development.

Parasuraman, A . Zeithaml, VALAREI \& Berry, Leonard .(1985) ." A Conceptual model of service quality and its implications for future research". Journal of marketing. vol.49, pp 4150.

Parsaran., Zeitaml. (2010). Servoqual model, translation by Heidarzadeh and Hajiha., Tehran, Kavosh Publication.

Perez, Manuel sanches \& et al .(2007). " Effects of service quality dimension on behavioural purchas intentions " managing service quality. Vo1.17, No.2, pp134-151.

Purcărea, V. L., Gheorghe, I. R., \& Petrescu, C. M. (2013). The assessment of perceived service quality of public health care services in Romania using the SERVQUAL scale. Procedia Economics and Finance, 6, 573-585.

Riahi, B. (2012). Total Quality management in public sector (government). Tehran Industrial Research and Training Center.

Safari, H., \& Mohebbi Mansheh,O. (2011). Presentation of Supply Chain Quality Management Conceptual Model and its status in Iran Automotive Industry. Case study: Iran Khodro Co. Tehran University of Technology Industrial Management. Volume 8. Number 7.

Saghaei, A. (2009). Investigations of Six Sigma Influence in the Industry and Services of the World. The Second Lean Sixth Sigma International Conference, Tehran. Institute for Quality Studies. 